\title{
MESLEK FOLKLORU BAĞLAMINDA KIYI EGE KADIN BALIKÇI FOLKLORU ${ }^{1}$
}

\author{
Fisherwomen's Folklore by the Aegean Coast in \\ the Context of Occupational Folklor
}

Gönderim Tarihi: 31.10 .2016

Kabul Tarihi: 14.11.2016

\section{Pınar FEDAKÂR* Nükte Sevim DERDiçOK}

ÖZ: Her meslek grubu gibi balıkçılık da kendine ait özel birtakım teknik ve mesleki bilgi içermektedir. Bu bilgi, meslek folkloru kapsamında ele alınmaktadır. Bu makalede, meslek ve folklor ilişkisi, kadın balıkçılar örneğinde ele alınmış ve kadın balıkçılardan derlenen "anlatmalar", "halk takvimi" ve "halk inançları ve uygulamaları" incelenmiştir. Bu makalede kullanılan veriler, geniş kapsamlı bir saha araştırmasına dayanmaktadır. Veriler, Kıyı Ege'deki dört araştırma alanını oluşturan İzmir, Muğla, Çanakkale ve Balıkesir'deki kadın balıkçılardan, karşılıklı görüşme ve katılımlı gözlem yöntemleriyle derlenmiştir.

Anahtar Kelimeler: Kadın Balıkçı, Meslek Folkloru, Kıyı Ege, İzmir, Muğla, Çanakkale, Balıkesir.

ABSTRACT: Like any occupation, fishery involves a number of technical and occupational knowledge of its own. This knowledge is examined within occupational folklore. In this article, the relation between occupation and folklore is discussed in the case of fisherwomen's folklore, and "narratives", "folk calendar", and "folk believes and folk practices" collected from fisherwomen are analyzed. Material of this study is based upon an extensive field research project. Data collected through in-depth interviews and participant observation in four case-study locations which are on the Aegean Coast: Izmir, Mugla, Canakkale and Balıkesir.

\footnotetext{
${ }^{1}$ Bu çalışmanın temelini, 14-TDAE-002 No'lu Ege Üniversitesi Bilimsel Araştırma Projesi olan, İzmir, Muğla, Çanakkale ve Balıkesir illerini kapsayan "Kıyı Ege Kadın Balıkçı Folkloru" adlı proje ve bu projenin çıtıları kapsamında tamamlanan "Kadın Balıkçı Folkloru: İzmir ve Muğla Örneği" adlı yüksek lisans tezi oluşturmaktadır.

*Yrd. Doç. Dr., Ege Üniversitesi/Türk Dünyası Araştırmaları Enstitüsü/Türk Halk Bilimi Anabilim Dalı, pdonmez41@hotmail.com.

"* Doktora Öğrencisi, Ege Üniversitesi/Türk Dünyası Araştırmaları Enstitüsü/Türk Halk Bilimi Anabilim Dalı, nuktederdicok@yahoo.com.
} 

Balikesir.

\section{GİRiş}

Geleneksel mesleklerden biri olan balıkçılık, avlanma yöntemleri ve uygulamaları, özel araç-gereç kullanımı başta olmak üzere pek çok tekniği ve tecrübeye dayalı özel bilgiyi içerir. Bu nedenle balıkçı, hem teknik hem de kültürel bilgi birikimine sahiptir. Toplumsal cinsiyet alg1sı ve buna bağlı olarak ortaya çıkan rol paylaşımları sebebiyle "erkek mesleği" olarak kabul edilen bu meslek grubu içerisinde kadınlar da mevcuttur. Balıkçılığın yaşam biçimi ve çalışma şartları, sektör içerisindeki kadınlar için bazı engeller teşkil etse de Türkiye'de deniz, göl ve akarsularda balıkçılık yapan, balıkçılığı meslek edinmiş kadınlar bulunmaktadır.

Kadın balıkçılar pek çok mesleki bilgiyi geleneksel kültür içinde öğrenir ve aktarır. Örneğin, balık avlama teknikleri, denizde yol alma ve bulma, avın yerini tespit etme ya da hava durumunu anlamak gibi pek çok özel bilgi usta-çırak ilişkisiyle aktarılır. Bu bilgi, tecrübeyle desteklenmesi ve tecrübenin paylaş1lmasıyla tamamlanmaktadır. Bugün balıkçılık, elektronik teçhizat ve teknik donanımın kullanıldığı modern bir meslek haline gelmiş olsa da halk takviminin takip edilmesi, hava tahmini için deniz yüzeyi, bulutların yönü, yıldızların parlaklığı, rüzgârın esiş yönü ve hızı gibi halk meteorolojisinin uygulanmas1; balıkların uluslararası ortak adlarının yanında yerel adlandırılmalarının da kullanılması; tekne şekillerinden avlanma ekipmanlarına kadar teknik araç-gerece yerel isimler verilmesi ve mesleğe bağlı olarak yaratılıp aktarılan sözlü kültür ürünleri (fıkra, memorat, efsane vb.) geleneksel yapının etkisiyle şekillenmektedir. Örneklediğimiz tüm bu hususlar, mesleğe bağlı kültürel yapıyı; yani "meslek folklorunu" oluşturan temel taşlardır.

Kadın balıkçı folklorunu belirli yapılardan oluşan bir bütün olarak ele aldığımızda, meslek seçimi, mesleği öğrenme, meslekî aşamalar ve geleneksel uygulamalar gibi temel birimlerin erkek balıkçılardan farklılık gösterdiğini ve buna bağlı olarak da balıkçılık mesleği içerisinde ayrı bir kültürel yapı oluşturduklarını söylemek mümkündür. Ege Üniversitesi Rektörlügü Bilimsel Araştırma Projesi olarak tamamlamış olduğumuz "Kıyı Ege Kadın Balıkçı Folkloru" (2015) adlı proje ve proje sahasından iki şehre bağlı olarak tamamlanan yüksek lisans tezi (Derdiçok, 2015) kapsamında yaptığımız alan araştırması sırasında Çanakkale, Balıkesir, İzmir ve Muğla illerinden 52 kadın balıkçı ile yapılan görüşmeler sonucunda, ustası eşi ya da babası olan; yani mesleği daha 
dar bir çerçevede öğrenmek, uygulamak ve aktarmak durumunda kalan kadın balıkçıların, meslekleri etrafında şekillenen inanma unsurlarına bağlı kaldıkları ve bu inanma unsurlarıla ilgili olan anlatmaları daha sık aktardıkları tespit edilmiştir. Örnek vermek gerekirse; deniz yaratıkları, özellikle deniz kızı hakkındaki inanma ve anlatmalar kadın balıkçılar tarafından sıklıkla yaratılıp aktarılmaktadır. Benzer şekilde, balıkçılıkla ilgili olarak anlatılan/söylenen "efsane”, "deyim", "atasözü", "tekne isimleri", "balık isimleri", "alkış (dua)" ve "kargış (beddua)"; düzenlenen "festivaller"; "nazar", "bolluk ve bereket" inancı ve bu inanca bağlı olarak yapılan uygulamalar; balık başta olmak üzere çeşitli deniz ürünleriyle yapılan yemeklerin tarifi gibi daha çok balıkçı kadınların yarattığı, uyguladığı ve aktardığı kültürel öğeler, kadın balıkçı folkloru içerisinde değerlendirilebilir.

Kadın balıkçıların kültürel ürünlerinin hem kadınlar özelinde hem de meslek grubu bakımından balıkçılık genelinde özel bir kültürel alan oluşturduğunu belirtmek gerekir. Meslek içerisinde cinsiyetleri sebebiyle bir "grubu" oluşturan kadın balıkçlar, meslekleri etrafında şekillenen kültürel yapı ile meslek folkloruna sahiptir. Konunun daha iyi anlaşılabilmesi için "meslek folkloru" terimi üzerinde durmak yerinde olacaktır.

Meslek, eğitim, cinsiyet, yaş, etnik köken, din, dil vb. gibi çeşitli birleştirici faktörler halkı oluşturur ve halkı oluşturan her bir bireyin birbiriyle etkileşim halinde olmasını sağlar. Çünkü bu olgulardan her biri, bireylerin ortak bir amaç doğrultusunda birleşmesine ve belli bir gelenek oluşturmasına zemin hazırlamaktadır.

Bu makalenin konusunu oluşturan meslek folklorundan örnek verecek olursak, meslekleri doğrultusunda bir araya gelmiş olan her bir grubun kendine ait bir folkloru olduğunu söylemek mümkün olacaktır. Bir halkı birbirine bağlayan "meslek" olgusu, halkın kendi geleneklerini yaratmasını sağlar ve aynı zamanda, sahip olduğu bu gelenekleri aktarması ve yaşatarak koruması için ortam hazırlar (Ekici, 2008: . 33-38).

“Meslek folkloru, köyden kente çalışma hayatı etrafında şekillenmiş folklor ürünlerini içeren bir kavramdır" (Duymaz ve Şahin, 2010: 104). Meslek folkloru terimi, Amerika ve Avrupa'daki “occupational folklore” teriminin karşılığı olarak kullanılır. Bazı folklorcular, "organizational folklore" terimini de "meslek folkloru ile aynı anlam ve bağlamda kullanmaktadır. Ancak, bu terim biraz daha karmaşık kurumsal yapılara işaret etmektedir (McNail, 2013: 6770). Meslek folkloruyla ilgili çalışmalarda, anlatmalar ve jargonu içeren sözlü şekillerin yanında kıyafetler, gayri resmi bir şekilde öğrenilen ve icra edilen beceri ve teknikleri de içermektedir (McCarl, 1986: 71). Meslek folkloru terimi, Türkiye'de ilk defa Ali Duymaz ve Halil İbrahim Şahin'in meslek folkloru ve 
pirleriyle ilgili makalesi (Duymaz ve Şahin, 2010), meslek folklorunun kapsamlı olarak ele alan ilk çalışmalar arasında yer alır (Aça, 2015: 126).

Meslek folkloru, köyden kente geleneksel, yarı geleneksel ve güncel meslekler ile kullanılan geleneksel ve modern yöntemleri kapsayan çalışma hayatı etrafında şekillenmiş halk bilgisi ürünlerini içeren bir kavramdır. Başka bir ifadeyle, meslek üyelerinin kendi aralarında oluşturdukları ortak dilleri, sözlü kültür ürünleri, geleneksel uygulamaları, inanışları, iş için gerekli âletlerin yaratımı ve kullanımı hakkındaki bilgileri, giyim tarzları, çalışma hayatıyla ilgili düşünceleri meslek folkloru kapsaminda incelenmektedir. Meslek folkloru, sadece meslekî jargon ve anlatıların sözlü formlarını değil; aynı zamanda herhangi bir çalışma grubundaki bireyler tarafından gerçekleştirilen ve gayri resmi yolla öğrenilen çeşitli beceri ve tekniklerin yanı sıra söz konusu meslek grubu etrafında şekillenen geleneksel uygulamaları da kapsamaktadır (Derdiçok, 2015: 29).

Meslek folkloru bağlamında ele aldı̆̆ımızda; balıkçılar, madenciler, doktorlar, saatçiler, fırıncılar gibi, belli bir meslek üyelerinin bir grubu oluşturduğunu ve birbirleriyle olan etkileşimleri sonucu genel anlamda grup folkloru; özel anlamda ise meslek folkloru adını verdiğimiz yapıyı meydana getirdiklerini söylemek yerinde olacaktır.

Balıkçılar da toplumsal yapıda meslekleri doğrultusunda bir araya gelmiş olmaları dolayısıyla grup folklorunun özel bir alanı olan meslek folkloru kapsamında ele aldığımız bir gruptur. Bu makalede, küçük ölçekli balıkçılar ele alınmıştır. Çalışma alanımız olan Kıyı Ege'de (Çanakkale, Balıkesir, İzmir ve Muğla illeri) balıkçılık faaliyetleri daha çok kıyı balıkçılığı üzerinde yoğunlaşmıştır. Kıta sahanlığının dar ve kıyıların girintili çıkıntılı olması gibi faktörlerin etkili olduğu bu durum, geleneksel-küçük ölçekli balıkçılığı ön plana çıkarmıştır. Geleneksel-küçük ölçekli balıkçılık, kıyı sürütme ağları, kıyı oltaları, paraketeler, kıyı uzatma ağları, kıyı gırgırları, dalyanlar ile yapılan balıkçılık faaliyetlerini kapsar. Türkiye'de toplam 20.289 balıkçı gemisi vardır. Bunların 3124 adedi içsularda balıkçılık yapmaktadır. Denizlerde çalışan 17.165 balıkçı gemisinin 15.326 adedi 12 metreden küçük ve genelde kıyı balıkçılı̆̆ı yapan küçük ölçekli balıkçı gemileridir (TUİK, 2011).

Küçük ölçekli balıkçılığa bağlı meslek folkloru, araştırma alanı bakımından oldukça geniştir. Bu noktada araştırma konusu edilen grup, cinsiyet odaklı olarak daraltılmış olan "kadın balıkçılar" dır.

Makalede, grup olarak seçtiğimiz "kadın balıkçılar"ın hem meslek hem de cinsiyetleri doğrultusunda oluşturdukları meslek folkloru, yukarıdaki tanım kapsamında da ifade etmiş olduğumuz "anlatmalar", "halk takvimi ve meteorolojisi" ve "halk inançları ve uygulamalar" kapsamında ele alınacaktır. 


\section{ANLATMALAR}

Bu başlık içerisinde, meslek folkloru tanımında "sözlü kültür ürünleri" olarak ele aldığımız efsane, memorat, deyim, atasözü, selamlaşma sözleri, alkış-kargış ve tekne ile balık adları ele alınmıştır. Söz konusu sözlü kültür ürünleri deniz, balık ve balıkçılık ile ilgili olarak kadın balıkçılardan derlenmiştir. Kadın balıkçılardan derlenen efsane, memorat, deyim, atasözü, selamlaşma sözü, tekne isimleri ve balık isimleri, alkış, kargış metinleri balıkçı kadınlar etrafında oluşan meslek folklorunun önemli bir parçası olarak dikkati çekmektedir.

Kadın balıkçılardan derlenen efsaneler, etiyolojiktir; yani açıklayıcı işlevi görür. Yapısal olarak uzun olmayan, büyük çoğunluğu denizkızı ile ilgili ve herhangi bir ismi açıklamaya yönelik olarak anlatılan efsane metinleri ile karşılaşılmıştır. Özellikle bir avlanma tekniği ve aracı olan paraketenin ismi ve nasıl ortaya çıktığı ile ilgili çok sayıda anlatma vardır. Bunlardan biri kıyı Ege'de balıkçılar tarafından çok kullanılan paraketeyle ilgilidir:

"Paraketenin ismi aslında belekadi. Bunu Yunanl bir bayan icat etmiş. Yunanlı bayan balıkçıymış. Kocasıyla balı̆̆a gidiyormuş. Yunanlı kadının doktor bir sevdiği varmış. Kocasıyla devamlı balı̆̆a gittiği için ben sevdiğimle nasıl buluşabilirim, nasıl bir iki saat boş kalabilirim diyerek kadın düşüne düşüne bunu icat etmiş. Çünkü paraketeyi, seleyi dökeriz yere; temizlemesi en az iki saat sürer. Onu döktü̈̆̈̈̈n zaman da bitmeden tuvalete bile gidemezsin. Onun başından kalkamazsın. Yunanlı kadın da böyle yapmış."(Derdiçok, 2015: 45).

Yukarıdaki anlatmada adı geçen parakete ile ilgili olan metinler, hem kadın balıkçılar hem de erkek balıkçılar arasında bilinmekte ve aktarılmaktadır. Efsane metinleri, balıkçılar tarafından daha çok paraketeyi temizleme ve paraketeye yem takma işlemleri sırasında bizim isteğimiz üzerine anlatılmıştır.

Çoğunlukla kadın balıkçılar tarafından inanılan ve buna bağlı olarak da aktarılan denizkızı hakkındaki anlatmalar, olağanüstü varlık olarak kabul edilen denizkızının balıkçılara yardımcı olması gibi işlevsel bir rol oynamaktadır:

"Balıkçı sessizce denizkızına yaklaşmış. Ona çatal iğne takmış. Çatal iğne taktı̆̆ı zaman gidemezmiş, orada kalırmış. Alt tarafı balık, üst tarafı kadına benziyormuş. Çok güzelmiş. Adam çok fakir, gariban biriymiş. Borcu da varmış. Adam borçlarını nasıl ödeyeceğini düşünürken denizkızı, adamı zengin etmiş. Ama adamdan da kendisini bırakmasını istemiş. Her bir insan denizkızın göremezmiş; ama o adam görmüss. Adam nereye ă̆ atsa balıkları sürüyüp geliyormuş. Elleri varmış, ayakları yokmuş. Ayakları balıkmış." (Derdiçok, 2015: 46).

Bunların dışında, "Genelde ada kenarında, taşlıkta yaşadı̆̆g için o balığa adabeyi demişler. Ama eski ismi iskorpittir.", "Çingene palamutu, palamut zamanından önce 
çıkan bir palamut. Biraz kof olduğu için, zamanından önce olduğu için çingene palamutu demişler." (Derdiçok, 2015: 46) gibi balık isimleri gibi konuların açıklanması hakkındaki anlatmalar; "nasıl", "neden" ve "niçin" sorularına cevap verici niteliktedir.

Kadınların aktardığı memoratlar ise, "uyarıcı" işlevi görmekte; denizde gidilmemesi gereken yerler ya da avlanılmaması gereken durumlar ile ilgili olarak anlatılmaktadir:

"Gece denizde su perileri olurmuş. Buna Ahmet de denk gelmiş. "Denizin içinden bir ışık çıktı. O ışıktan sonra çı̆̆lık sesi duyuldu." dedi. Onun için ben şimdi gece nerede olursa olsun denizin ortasında ışık yanan yerde balık avlamam. İster inansın ister inanmasın." (Derdiçok, 2015: 49).

Efsane ve memoratlarda olduğu gibi, deyim, atasözü, selamlaşma sözleri, alkış ve kargışlar da meslekleri etrafında şekillenmiştir.

Deyim ve atasözü gibi anlatmalar, kadın balıkçlardan ve karşılaştırma yapma amacıyla kadın balıkçıların eşleri olan erkek balıkçılardan derlenmiştir. Deyimler ve atasözleri, bizim isteğimiz üzere değil; sohbet sırasında yeri geldikçe balıkçılar tarafından aktarılmıştır. Kimi inanış ve gelenekleri bildiren deyim ve atasözleri, kadın balıkçı folkloru etrafında şekillenmiş, meslekleri ile alakalı birtakım gözlem ve deneme sonucu elde ettikleri bilgiye dayanmaktadır.

Gündelik yaşam içerisinde iletişimin sağlanmasını ve devam etmesini sağlayan öğelerden biri olan selamlaşma, kişiler arasındaki iletişimin başlaması, devam etmesi ve sonlanmasında önemli bir rol oynayan dil ve davranış şekilleri ile gerçekleşmektedir. Hem kadın hem de erkek balıkçılardan selamlaşma sözü olarak en sık duyduğumuz ve derlediğimiz metin, "rastgele"dir (Derdiçok, 2015: 52). Rastgele, balıkçılar arasında çok yaygın olarak kullanılan bir selamlaşma sözü olarak karşımıza çıkar.Bu söz, hem selamlaşma hem de iyi dilek taşımaktadır.

Kadın balıkçılardan hem mülakat hem de gözlem yöntemleriyle derlemiş olduğumuz "Bereket versin.", "Allah daha çok versin.", "Allah ağlarını doldursun.", "Allah kocana daha çok balık versin." (Derdiçok, 2015: 58) gibi alkışlar, daha çok balık yakalamak ve denizde başa gelebilecek kötülüklerden korunmak amaçlıdır. Alkışlar kadar sık olarak karşılaşmadığımız kargışlara ise derlenen tek örnek; "Allah trol versin!" şeklindedir. Uzun yıllar büyük ölçekli balıkçılıkla geçimini sağlayan kadın balıkçılardan biri, işinin zor olduğunu belirtmek için beddua edeceği zaman bu şekilde söylediğini ifade etmiştir.

Bunlar dışında, tekne ve balık isimleri de genelde balıkçılar özelde ise kadın balıkçılar sayesinde somut olmayan kültürel mirasa yapılmış bir katkıdır. Şükrü Elçin'in "minyatür eserler" (Elçin, 1997: 476) benzetmesinden yola çıkarak 
meslek folkloru ve kültürel bellek aktarımında önemli rol oynayan tekne isimleri ve balıkçıların kendi aralarında özel bir dil olarak ortaya koydukları balıkların yerel adlandırılmaları da bu başlık altında ele alınmıştır.

Teknelerin büyük çoğunluğunun ismi önceki sahiplerinden kalmadır; ancak teknelerine kendileri ad veren balıkçılar ya kendilerinin ya da çocuklarının isimlerini tercih etmiştir. Balık isimleri ise hem Türkçedeki genel kullanımı hem de yerel kullanımı ile karşımıza çıkmaktadır. Karşılaştı̆̆ımız 46 balık isminden 29'u Türkçedeki genel kullanım (dülger, bakalyaro, barbunya gibi), ; 17'si ise yerel kullanıma (peygamber balığı, berlam, barbun gibi) aittir (Derdiçok, 2015: 55-56).

\section{HALK TAKVIMII-METEOROLOJISİ VE YÖN BULMA}

Bu kısımda, gününün neredeyse tamamını denizde geçiren kadın balıkçılar için son derece önemli olan yön bulma, halk takvimi ve meteorolojisi ile ilgili bilgilere yer verilecektir. Kadın balıkçıların söz konusu bilgilerine değinmeden önce halk takvimi ve meteorolojisinin ne olduğu üzerinde durmak yerinde olacaktır.

Bu bağlamda, Gürbüz Erginer'in halk takvimi tanımına bakmak gerekir:

"Herhangi bir yöre insanının, temelde kültürel bir miras olarak edindiği; doğal olgularla, toplumsal kurumlar ve olgular arasındaki uzun süreli deneyimlere dayal ilişkinin kurulduğ u dinsel, tarihsel, töresel, eğitsel, inançsal, hukuksal, tarımsal, siyasal, ekonomik bağın anımsama ve anımsatma görevini üstlenmiş olan zaman-hayat ikilisinin sistemli bir dizgesi" (Erginer, 1984: 22).

Erginer' in "ekolojik", "doğal", "dinsel", "ekonomik" ve "toplumsal ve toplumlararası olaylar" çerçevesinde oluştuğunu ifade ettiği halk takviminde, balıkçılık söz konusu olduğunda "ekonomik" etkenin ön plana çıktığını görmekteyiz. Balıkların hangi aylarda avlandığını bilen balıkçılar, bazı ayları, o ay içerisinde avlanan balıkların isimleri ile adlandırmaktadır.

Kıyı Ege'nin kadın balıkçılarından halk takvimi ile ilgili olarak derlediğimiz metinler, özellikle denize çıkılması uygun görülmeyen çok sıcak havaların hangi aylara denk geldiği ve nasıl isimlendirildiği ile alakalıdır.

Geçimini balıkçılıktan kazanan kadın balıkçı için yılın hangi dönemlerinde veya hangi havalarda denize çıkılması gerektiği hayatî bir konudur. Bu çerçevede oluşturulmuş olan halk takvimi de çoğunlukla tüm kadın balıkçılar tarafından bilinmekte, uygulanmakta ve aktarılmaktadır.

Halk takvimi ve meteorolojisi konusunda fazlaca bilgisi olan kadın balıkçılar, kendileri için tehlikeli olabilecek ve estiği zaman balığa çıkılmaması gereken rüzgârları bilmekte; kimi zaman hava durumlarından kimi zaman da havanın 
kendini belli etmesi gibi geleneksel yöntemleri kullanarak bilgilerini teyit edebilmektedir.

"Sakin havalar"da, "lodos" ve "poyraz" çok esmediğinde denize çıkılması gerektiği; gelişen teknoloji sayesinde internetten sürekli olarak hava ve deniz durumunun takibinin yapıldığı; gökyüzüne bakarak bulutların durumundan havanın anlaşılabileceği; rüzgârların özelliklerine göre hangi isimleri aldı̆̆ı gibi halk takvim ve meteorolojisini ilgilendiren tüm önemli hususlar kadın balıkçılar tarafından bilinmekte ve aktarılmaktadır.

Kadın balıkçılarla yaptığımız görüşmeler sırasında özellikle geceleri yön bulma konusunda yardımcı unsur olarak karşımıza çıkan yıldızlar da meslek folkloru açısından önemli rol oynamaktadır.

\section{TOPLUMSAL İNANÇ VE UYGULAMALAR}

\section{Kutlamalar}

Bu kısımda, kadın balıkçılardan derlediğimiz balık, balıkçılık veya denizle ilgili olarak kutlanan bayramlar ve festivallere yer verilmiştir.

Çalışma alanımız olan Kıyı Ege'de balık ya da denizle ilgili olarak kutlanan bayram sayısı oldukça azdır. Yukarıdaki açıklamalara göre kaynak kişilerimizin "bayram" olarak ifade ettikleri uygulamalar sadece Sığacık'ta (İzmir) kutlanan Sığacık Balık Bayramı'dır. Sığacık Su Ürünleri Kooperatifi tarafından senede bir defa yapılan bayramda, bayrama gelen herkese balık ekmek dağ1tılmaktadır (Derdiçok, 2015: 61). Bu kutlamada, kadın balıkçıların yanı sıra erkek balıkçıların eşleri de kutlamalara katılmaktadır.

6 Mayıs 2015 tarihinde, alan araştırmamızın Muğla ayağı dahilinde gittiğimiz Bozburun'da Hıdırellez kutlamalarına dair çeşitli uygulamalar tespit edilmiştir. Özellikle kadın balıkçlar teknelerine binerek etraftaki adalara gidip piknik yaparlar. Birlikte yemekler yenir, oyunlar oynanur ve dilekler dilenerek denize taş atılır. Balıkçıların Hıdırellezde Hıdır'1 tuttuğu söylenmektedir (Derdiçok, 2015: 61).

Festivallerin yapısı, sırasıyla; açılış töreni, ritüel, drama ve yarışma, şölen (yemek), dans ve müzik ile olayın bitirilişi unsurlarından oluşmaktadır ve kadın balıkçıların, Seferihisar ve çevresinde dahil olduğu festivaller de bu yapıya uygundur (Derdiçok, 2015: 59).

Bu olay yapısını takip eden ve kadın balıkçılar başta olmak üzere söz konusu alandaki balıkçılarla yapılan görüşmelerden elde edilen bilgilere göre, Gelibolu Sardalye Festivali, Foça Balıkçı Festivali, Urla Özbek Köyü Deniz ve Deniz Ürünleri Şenliği, İzmir Hamsi Şöleni ve Aliağa Hamsi Şöleni her yıl düzenli olarak kutlanan festivallerdir. 
Yukarıda adı geçen festivaller genellikle çok sayıda insanın katılımı ile gerçekleşmekte; çoğunlukla açılış töreni, deniz temizliği, çeşitli yarışmalar, mezat, balık-ekmek dağıtımı gibi yapılardan oluşmaktadır (Derdiçok, 2015: 62).

\section{Adak-Kurban}

Her kültürde insanüstü güce yaklaşma ve onunla iletişim kurma amacı etrafında şekillenen kurban, insanlık tarihi kadar eskidir. Kurban olgusu, çeşitli inanç ve uygulamaları da beraberinde getirmiştir.

Gürbüz Erginer tarafından "periyodik kurbanlamalar”, "adak kurbanlamalar1" ve "şölenlik, törenlik kurbanlamalar" olarak üç başlık altında değerlendirilen Anadolu'daki kurban uygulamaları, kadın balıkçılar tarafından da hayata geçirilmektedir. Ancak Erginer'in yapmış olduğu üçlü tasnif içerisinden kadın balıkçılar etrafında yaygın olarak uygulananı adak kurbanlamalarıdır.

Erginer adak kurbanlamalarını şöyle açıklamıştır:

"Bu grupta yer alan kurbanlamaların genellikle belirli bir zamanda gerçekleştirilmesi gibi kısıtlayıcı koşulu ve periyodik yapısı yoktur. Bu kurbanlamalar, koşullu ya da koşulsuz adağın (nezirin) genellikle gerçekleşmesi durumunda belirginlik kazanmaktadır." (Erginer, 1997: 170)

Tanımdan hareketle, denizde tehlikeli bir durumda kalan balıkçıların, karaya sağ salim ulaşabilmek için adak adamaları ve karaya çıktıklarında da bu adaklarını gerçekleştirmeleri, adak kurbanlamaları olarak ifade edilebilir. Bu konuda karşımıza çıkan inanç ve uygulamalar ise, yeni alınan tekne için kurban kesilmesidir. Temel olarak karşılıklı bir eylem olan kurban, değiş-tokuş ilkesine bağlı olarak gerçekleştirilmektedir. Kadın balıkçılar tarafından da uygulanan bu tür kurbanlamalar da bunun kanıtı olacak niteliktedir. Böylece, insanoğlu doğaüstü güçleri kendi tarafına çekerek gelecek tehlikelerden korunmuş olacaktır (Derdiçok, 2015: 63).

\section{Bolluk ve Bereket Ritüelleri}

Bereket, ekmeğini denizden; yani balıktan kazanan kadın balıkçılar için son derece mühimdir. Bu sebeple, kadın balıkçılar avın bereketli geçmesini sağlayacak çeşitli inanma ve uygulamaların bilgisine sahiptirler ve bu bilgiyi yaşatarak korumaktadırlar.

Avın bereketli geçmesi için kadın balıkçılar tarafından yapılan uygulamalar; dua etmek, tekneye sağ ayakla girmek ve küçük balıkları büyümesi için tekrar denize bırakmaktır. Kadın balıkçılar bu pratiklere önem göstermekte ve uygulamaktadırlar (Derdiçok, 2015: 64). 


\section{Nazar}

Boratav tarafından "kimi insanların bakışlarındaki zararlı güç ve bu nitelikleriyle, bir kişiye, bir hayvana ya da bir nesneye bakmakla, canlı üzerinde hastalık, sakatlık, ölüm, nesne üzerinde sakatlanma, kırılma gibi olumsuz bir etkinin meydana gelmesi anlamını almıştır." (Boratav, 2003: 133-134) şeklinde açıklanan nazar ve nazar inancı, kadın balıkçılarda son derece yoğundur.

Kadın balıkçılar tarafından, tutulan balıklar(a) "göz değmesin”, "göze gelmesin" diye özellikle "kem gözlü" olduğu düşünülenlerden saklanır, teknelere nazar boncukları asılır, balık tutulurken ya da balık tutmaya yarayan ağlar yapılırken "Maşallah" denmesine dikkat edilir (Derdiçok, 2015: 65-66).

\section{SONUÇ}

İzmir, Muğla, Çanakkale ve Balıkesir illerinde gerçekleşen alan araştırması sonucunda Kıyı Ege Bölgesi'nin kadın balıkçılarının kendi aralarında meslekleri çerçevesinde oluşturdukları geleneksel bilgi meslek folkloru olarak incelenmelidir.

Bu makalede konu edilen meslek folkloru hakkında yaptığımız saha araştırması kapsamında Kıyı Ege'nin dört ili, 13 ilçesi ve 7 köyünde toplam 87 balıkçı ile görüşülmüştür. Bunlardan 52'si kadın balıkçıdır. Bu kadınlar, balıkçılık, ağ yapımı ve tamiri, midyecilik, mezatta balık satma işlerini yapmakta; aynı zamanda bir kısmı pansiyonculuk, çiftçilik ve tekne turu gibi ek işlere de sahiptir. 46 kadın, balıkçılık, 10 kadın ağ yapımı ve tamiri, 3 kadın ise balıkçılıkla ilgili yan alanlarda görev almaktadır. Balıkçılık dışında ikinci bir işle uğraşan kadın oranı \%6'dır. Genellikle 50-60 yaş arası olan balıkçı kadınlarla görüşmeler yapılmıştır. Kadınların \%75'i mesleği eşinden, \%8'i hem eşinden hem babasından, \%4'ü annesinden, \%13'ü babasından ya da dedesinden öğrenmiştir. Kadınların \%82'si eşiyle, \%4'ü babası veya oğluyla, \%3’ü ablasıyla ve \%3'ü yalnız başına ava çıkmaktadır. Görüşme yaptığımız kadın balıkçılar, küçük ölçekli balıkçılık kapsamında karşımıza çıkan aile balıkçılı̆̆ı içinde kendini göstermektedir. 52 kadın balıkçı ile yapılan görüşmeler sonucunda 13 saatlik kamera kaydı, 8 saatlik ses kaydı ve 3.962 fotoğraf elde edilmiştir. Söz konusu bölgede yapılan alan araştırması ve alan araştırması sonucunda elde edilen tüm bilgiler ışı̆̆ında, kadın balıkçıların oluşturdukları geleneksel yapının meslek folkloru adını verdiğimiz inceleme alanında önemli bir rolü olduğunu söyleyebiliriz.

Herhangi bir meslek grubuna ait olan sözlü kültür ürünleri, dil, giyim tarzı, iş için gerekli teknik ve bilgi, meslek hakkında oluşan duygu ve düşünceler, toplumsal yapıyı oluşturan önemli bir parçayı ve bireyin kimliğini gözler önü- 
ne sermesi bakımından son derece önemlidir. Kadın balıkçı folkloru da genel olarak halkbilimi alanında özel olarak ise meslek folkloru kapsamında özel bir alanı ifade etmektedir. Kadın balıkçı folkloru söz konusu olduğunda hem cinsiyet hem de meslek ortaklıkları devreye girmektedir. Bu da meslek grubu arasında oluşan geleneksel yapının iki koldan beslenmesi için son derece elverişli bir ortam hazırlamaktadır. Erkek balıkçılar, mesleği daha geniş bir alanda öğrenme şanslarından dolayı mesleğin geleneksel yapısıyla ilgili bazı hususları unuturken kadın balıkçılar, cinsiyetleri sebebiyle mesleği daha dar bir alanda öğrendikleri için geleneksel yapının özellikle inanç ve aktarım boyutunu yaşatarak korumaktadır. Bu durum, cinsiyet ve meslek kanalıyla beslenen ve kültür ya da folklor bakımından zenginleşen kadın balıkçı folklorunun bahsedilen özelliğiyle ilgili en önemli kanıttır. Türk halk bilimi alanındaki meslek folkloru çalışmaları içinde "kadın" odaklı olarak yapılan ilk çalışmalardan biri olan bu makale, Kıyı Ege kadın balıkçıları gibi özel ve neredeyse hiç çalışılmamış bir alandan Türk halk bilimi ve özellikle meslek folkloru araştırmalarına kaynaklık edecek veri sağlanmıştır. 


\section{KAYNAKÇA}

Aça, M. (2015). “Meslek Folkloru Araştırmaları Tarihine Bir Bakış.” Uluslararası Türk Dünyası Kültür Araştırmaları Dergisi, 1, 111-137.

Boratav, P. N. (2003). 100 Soruda Türk Folkloru. İstanbul: Mas Matbaacılık.

Derdiçok, N. S. (2015). Kadın Balıkçı Folkloru: İzmir ve Muğla Örneği. Yayımlanmamış Yüksek Lisans Tezi, Ege Üniversitesi, İzmir.

Duymaz, A. ve Şahin, H. İ. (2010). “Meslek Folkloru Kapsamında Geleneksel Mesleklerdeki Pir İnancı ve Hikâyeleri Üzerine Bir Değerlendirme." Milli Folklor, 87, 101-121.

Ekici, M. (2008). “Geleneksel Kültürü Güncellemek Üzerine Bir Değerlendirme." Milli Folklor, 80. 33-38.

Elçin, Ş. (1997). Ayvalık Limanına Bağlı Deniz Araçlarının İsimleri. Ş. Elçin, Halk Edebiyatı Araştırmaları II Ankara: Akçağ Yayınları, 476-483.

Erdem, S. (2012). Grup Folkloru ve “Özkültür". Milli Folklor, 94, 41-49.

Erginer, G. (1984). Uşak Halk Takvimi Halk Meteorolojisi. Ankara: Türk Tarih Kurumu Basımevi.

Erginer, G. (1997). Kurban: Kurbanın Kökenleri ve Anadolu'da Kanl Kurban Ritüelleri. İstanbul: Yapı Kredi Kültür Sanat Yayıncılık.

Kıyı Ege Kadın Balıkçı Folkloru Bilimsel Araştırma Projesi Sonuç Raporu. (2015). Proje Yürütücüsü: P. Fedakar, araştırmacılar: H. Göncüoğlu, N. S. Derdiçok. Ege Üniversitesi Rektörlüğü Bilimsel Araştırma Projeleri Şube Müdürlüğü, Proje No: 14-TDAE-002.

McCarl, R. (1986). “Occupational Folklore.” Folk Groups And Folklore Genres: An Introduction. Ed. E. Oring, Colorado: University Press of Colorado, Utah State University Press, 71-90.

McNeill, L. S. (2013). Folklore Rules: A Fun, Quick, and Useful Introduction to the Field of Academic Folklore Studies. Utah: Utah State University Press. 